ISSN 0001-6002/2010/52/3/167-172 Acta Médica Costarricense, (C2010 Colegio de Médicos y Cirujanos

\section{Characterization of the Use of Antiemetics in the Postoperative Period in Adult Patients Undergoing Surgery during January to May 2009 in a private hospital, Clínica Bíblica, in Costa Rica}

\author{
Natalia Apuy-Roldán ${ }^{3}$, José Miguel Chaverri-Fernández ${ }^{1}$, Mónica Monge- \\ Aguilera $^{3}$, Esteban Zavaleta-Monestel ${ }^{2}$
}

1. Facultad de Farmacia, Universidad de Costa Rica [Faculty of Pharmacy, University of Costa Rica]

2. Pharmacy, Hospital Clínica Bíblica

Pharmacy Student, Facultad de Farmacia, Universidad de Costa Rica [Faculty of Pharmacy, University of Costa Rica]

Abbreviations: PONV, Postoperative nausea and vomiting

Contact information:

José Miguel Chaverri

PO Box. 11501-2060

E-mail: jose.chaverri@ucr.ac.cr

\section{Abstract}

Aim: To evaluate and characterize the pharmacotherapeutic approach with antiemetics during the postoperative, in adult patients undergoing surgery at the Hospital Clínica Bíblica (a private hospital in Costa Rica).

Methods: Patients (with ages between 18 and 75), who underwent surgery and received some kind of prophylactic antiemetic before the procedure, were selected. Patients that had hospitalization periods shorter than 24 hours were excluded.

Results: Prophylactic antiemetic therapy utilized in this hospital includes: granisetron, metoclopramide, dexamethasone, and dimenhydrinate. Granisetron, either alone or combined, was the most used antiemetic in $81 \%$ of the cases. The most commonly used combination was dexamethasone and granisetron in $57 \%$ of the cases. Without considering the surgical procedure, the incidence of postoperative nausea and vomiting (PONV) was $12 \%$ in patients taking granisetron, $25 \%$ with metoclopramide, $9 \%$ with dimenhydrinate, $13 \%$ with dexamethasone and $14 \%$ with other antiemetics. The surgeries with the greater incidence of PONV were orthopaedic surgery, 30\%, and laparoscopic surgery, $28 \%$. Finally, in cases in which fentanyl was used as an anesthetic, $18 \%$ of the patients presented PONV, whereas in patients cases were fentanyl was not used, the rate was $9 \%$.

Conclusion: Despite the widespread use of prophylactic antiemetics, PONV still occurs in patients at this private hospital. In spite of the wealth of knowledge in this field, physicians have not yet found an algorithm capable of the total prevention of PONV. Each patient's individual risk and satisfaction should be taken into account. Further research on this matter must continue in order to unify and improve criteria for PONV treatment.

Keywords: nausea, vomiting, postoperative, anesthetics, antiemetics, postoperative nausea and vomiting.

Received: December 1, 2009

Accepted: April 20, 2010 
Nausea is defined as an unpleasant sensation in the throat and epigastrium, accompanied by the urgent need to vomit, vomit understood as the forced expulsion of gastric contents. ${ }^{1}$

An estimated 75 million patients worldwide require anesthesia every year. Nausea and vomiting are common in one third of them during the postoperative period. Although surgical and anesthetic techniques, as well as pharmacological treatment, is constantly improving, the incidence of postoperative nausea and vomiting (PONV) is still frequent in a significant range $(20-30 \%),{ }^{2}$ and can elevate up to $80 \%$ in patients with various risk factors. ${ }^{3,4}$

Although the precise etiology of PONV is not well elucidated, experts suggest a multi-factor origin. ${ }^{5}$ Among risk factors, it is possible to find: being a female, having a history of motion sickness or of emetic episodes in previous interventions, use of ketamine, opiates and halogenated agents. ${ }^{6-8}$ In relation to surgery, the most emetogenic are orthopaedic, laparoscopic and gynecologic procedures. $^{9}$

PONV delays the patients' discharge after outpatient surgery, creates discomfort and may increase tension over suture. ${ }^{7}$ The PONV also increases the risk of pulmonary aspiration, which can lead to pneumonia or pneumonitis, dehydration and electrolyte imbalances, an esophageal rupture (Boerhaave syndrome), Mallory-Weiss syndrome, a gastrointestinal bleeding, and increased intracranial pressure. $^{10,11}$

The study of PONV is important because they increase hospital costs and patient's stay; also they involve an extra investment of time by the nurses who eventually abandon other duties to address this type of events. ${ }^{12}$

In recent decades, the control of PONV has received less attention than pain control, despite being the most stressful complications for the patient in the postoperative period. ${ }^{13}$

There is evidence that appropriate use of antiemetic therapy can reduce PONV, and benefits can be obtained, both for the patient and for health personnel working at the hospital. ${ }^{12,14}$

Given the contradictions in the different clinical trials on the efficacy of antiemetics used in the postoperative period, it is necessary to endeavor to assess the use of these drugs and their effectiveness in national hospitals, also considering the lack of this type of studies and their clinical importance. ${ }^{16}$
The study aims to determine the frequency and combination of antiemetics available in this private hospital for the management and control of PONV; as well as relate the incidence of postoperative vomiting with the type of antiemetic used, type of surgery and the anesthetics used

\section{Methods}

Patients selected were those undergoing a surgical procedure and remained at the hospital for more than 24 hours, to which an antiemetic therapy was applied in the intraoperative or postoperative period, or at both times, with ages ranging from 18 to 75 , during the period January to May $2009 .^{17}$

Patients who were prescribed antiemetic drugs such as tricyclic antidepressants, phenothiazines, lorazepam and corticosteroids; or with symptoms of nausea, retching or emesis in the 24 hours before surgery were excluded, as it could interfere with the results.

Data collection was performed by preparing a registration form; information was obtained through each patient's medical record or through an interview with the nurse or the surgeons and anesthesiologists in charge of surgery.

The patients' condition (frequency of nausea, vomiting and any other relevant information) was documented during the 24 hours after the patient left the surgical procedure.

The need to add another antiemetic therapy, the number of PONV episodes before and after such treatment, anesthetics used during surgery, the patient's sex, age, type of surgery, comorbidities and previous medication; as well as some other useful parameters were recorded.

Data obtained was processed through the S.P.S.S. V 15.0 and Excel programs. For a more appropriate management of some results, the type of surgery was categorized. $^{8,18}$

This study was approved by the hospital's Medical Department, due to the absence at the time of a research ethics committee to validate it. 


\section{Results}

Out of all hospitalized patients undergoing any surgical procedure, 275 who met the inclusion criteria were selected: 61 men (22\%) and 214 women (78\%), with ages between 18 and 75 years (mean 42.7 years).

Of the 275 patients included, 219 were healthy (79.6\%) and 56 had comorbidies (20.4\%); the main diseases present were hypertension, diabetes mellitus and dyslipidemia. Regardless of the antiemetic used and the application period, the percentage of patients experiencing PONV was very similar in both healthy $(16 \%)$ and those with a previous personal disease (14\%).

From the surgical procedures included, 44.7\% were gynecological surgeries; $13.5 \%$, plastic surgeries; $13.1 \%$, laparoscopic surgeries; $12 \%$, orthopaedic surgeries; $5.5 \%$, abdominal surgery, and $11.3 \%$, other surgeries.

Of all patients who received antiemetics, $81.8 \%$ were treated with granisetron, alone or combined with other antiemetics, such as metoclopramide or dexamethasone. The most frequent dose of granisetron used was $1 \mathrm{mg}$; the remaining $18 \%$ used various combinations including dimenhydrinate, levosulpiride or metoclopramide. The use of dexamethasone together with granisetron was the most commonly used combination (57\%).

The proportion of patients experiencing PONV, despite the use of intraoperative prophylaxis drugs, was up to $25 \%$ when metoclopramide was applied, and less than $10 \%$ when dimenhydrinate was used (Figure 1).

Fentanyl (73.5\%), propofol (52.4\%), and sevoflurane (48.4\%) were the most commonly used anesthetics for surgery in the selected patients. When fentanyl was used as an anesthetic, vomiting occurred in $18 \%$ of patients, whereas in cases where fentanyl was not used, the rate of PONV was $9 \%$.

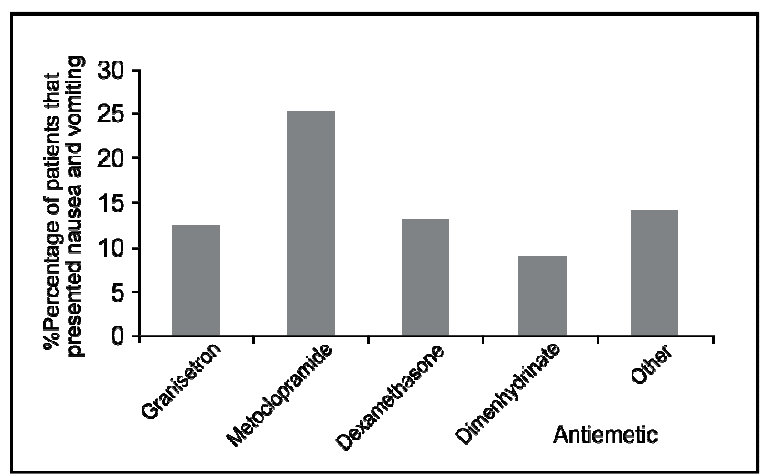

Figure 1. Proportion of patients that presented PONV after using different antiemetics in the intraoperative.

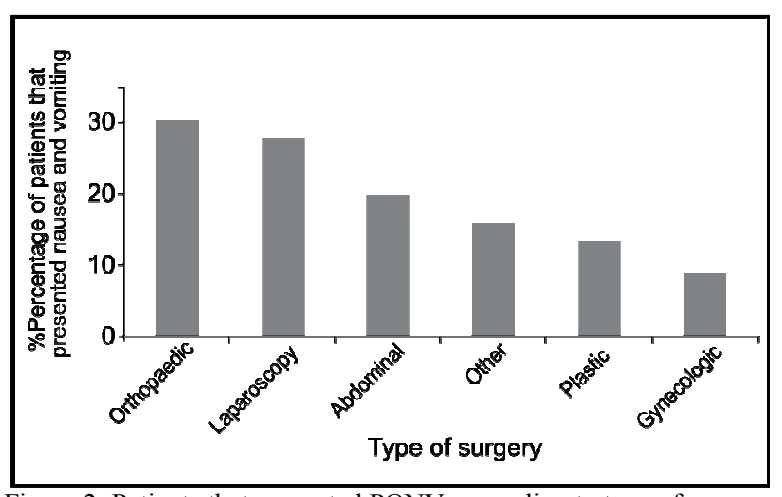

Figure 2: Patients that presented PONV, according to type of surgery

Of the total number of patients undergoing surgical procedures, not considering any association with the type of surgery or premedication, 44 suffered PONV (16\%) against 231 patients who did not (84\%); the proportion of patients with PONV, according to the type of surgery they undertook can be seen in Figure 2., were laparoscopic and orthopaedic surgery were the main cause of these symptoms, regardless of prophylactic use.

The percentage of patients with PONV and who also received general anesthesia was much higher (19\%), compared to the one for those treated with spinal anesthesia (9\%).

The lack of a homogeneous distribution of treatments received by patients is not effective in this case to establish use behaviors; however, it is useful to determine the most frequently used prescription trends by those that administer treatment.

The number of patients is sometimes very low, so it is difficult to quantify efficacy of all treatments provided. 


\section{Discussion}

One of the risk factors for PONV is to be a female. ${ }^{4,5}$ Notwithstanding said fact and because the study did not have an equal proportion of men and women, it was not possible to truly evaluate the gender incidence, as a risk factor for PONV.

The percentage of patients who presented PONV in the study was quite similar to the one obtained by different publications, were the incidence of PONV was similar to the results obtained in this hospital. ${ }^{11}$, $19-21$

In the study, orthopaedic surgeries, together with laparoscopic ones, presented the highest percentage of patients with PONV: $29 \%$ and 28\%, respectively. Findings in various publications validate the study's results, were laparoscopic cholecystectomy is one of the surgeries with the highest incidence of PONV, due to the stimulation of the mechanoreceptors in the

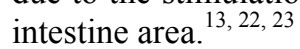

The vast majority of patients received granisetron as an antiemetic during surgery, as prophylaxis for PONV. Also drugs such as dexamethasone and metoclopramide were used. Studies show that when using this antiemetic, incidence of PONV is higher compared to setrons and dexamethasone. $8,18,20,23-, 5$

Granisetron was the most widely used antiemetic in the different surgeries, the dose used is considered optimal for antiemetic prophylaxis. ${ }^{16}$

In several studies, the antiemetic granisetron is administered in most cases as prophylaxis for PONV, and has demonstrated superiority compared to other drugs. 4, 26, 27

Dexamethasone was also used in a high percentage of the surgeries, most often in combination; because of this, high effectiveness was found, as the drug's effect enhances the chosen antiemetic agent. ${ }^{4,5,28}$

Patients who used fentanyl during anesthesia had a higher incidence of PONV than those who did not use it. This is consistent with that reported by other studies, in which the omission of this opioid reduced the need for antiemetics, as the incidence of PONV significantly decreased. $^{29}$
An algorithm that allows complete prevention of PONV has not been found, despite the vast amount of knowledge acquired in this field. Similarly, there is not a unified criterion as to the strategy that must be followed in order to prevent or treat PONV. The individual risk of every patient and its satisfaction must be taken into account; as well as the adverse drug reactions, the cost of the antiemetics and costs associated with readmissions that occurred because nausea and vomiting were not treated.

Given these findings, it is recommended that in the most emetogenic surgeries, such as orthopaedic and laparoscopic ones, prophylactic antiemetic therapy is used, specifically with drugs that have proven to be the most effective in clinical practice.

It is also recommended to exclude the use of fentanyl in surgical procedures whenever possible, as its use increases the likelihood of PONV.

Using drug combinations is an appropriate strategy to prevent PONV in the most emetogenic procedures.

Among the study's limitations, it should be noted that it was conducted with the population attending the private hospital, thus results can not be extrapolated at the national level. In addition, this study provides no statistical significance in its results, because it was not possible to have a proper proportion of patients of both sexes or the same proportion of patients in each surgery or types of drugs used; which makes comparative analysis with other studies difficult, although there are some apparent trends that coincide with published studies.

For this study, it was not possible to quantify adverse effects directly associated with the antiemetic because during the procedure, medical teams do not only apply these kinds of drugs.

Notwithstanding the above, it is expected that the study will be useful for future research in the same field, and that the findings in this private hospital can help unify and improve the prophylactic treatment of PONV; under an ideal framework, such a study should provide a significant population, separate according to type of surgery, drug, type of anesthetic and patient's sex, among other parameters; thus trends could be assessed without trouble, extrapolate results, analyze without problem the efficacy of drugs, and relate them to the patient's tolerance and other individual characteristics. 


\section{References}

1. González E, Delgado M. Estudio comparativo de la eficacia entre difenidol, ondansetrón y metoclopramida para la prevención y tratamiento de la náusea y el vómito postoperatorios en pacientes sometidos a intervención quirúrgica de oído y mastoides. Rev Esp Med Quir 2008; 13:153-8.

2. Bel I, Gambús P. Estratificación del riesgo, profilaxis y tratamiento de las náuseas y vómitos postoperatorios. Rev Esp Anestesiol 2006; 53: 301-311.

3. Ho K, Chiu J. Multimodal antiemetic therapy and emetic risk profiling. Ann Acad Med Singapore 2005; 34:196205.

4. Kushwaha B, Chakraborty A, Agarwal J, Malick A, Bhushan S, Bhattacharya P. Comparative study of granisetron and ondansetron alone and their combination with dexamethasone, for prevention of PONV in middle ear surgery. Internet Journal of Anesthesiology 2007; $13: 2$.

5. Wattwil M, Thorn S, Lovqvist A. Dexamethasone is as effective as ondasetron for the prevention of postoperative nausea and vomiting following breast surgery. Acta Anaesthesiol Scand 2003; 47:823-827.

6. Montejo K, González I, Perdomo J, González E, Domech A. Prevención de las náuseas y vómitos postoperatorios. Rev méd electrón [Seriada en línea] 2007 [10 de enero 2009],

29(4).En:http://www.cpimtz.sld.cu/revista\%20medica/an o\%202007/vol4\%202007/ tema13.htm

7. Rincón D, Valero J. Prevención de la náusea y el vómito postoperatorios. Rev Col Anest 2007; 35: 293-300.

8. Fujii, Y. The Utility of antiemetics in the prevention and treatment of postoperative nausea and vomiting in aatients scheduled for laparoscopic cholecystectomy. Current Pharmaceutical Design 2005; 11: 3173-3183.

9. Teran L, Hawkin J. The effectiveness of inhalation isopropyl alcohol vs granisetron for the prevention of postoperative nausea and vomiting. AANA J 2007; 75: 417-422.

10. Hamdan G. Midazolam: Un antiemético efectivo después de la cirugía cardíaca. Anesth Analg 2004; 99:339-43.

11. Sánchez M, López L, Pueyo F, Carrascosa F, Ortega A. A comparison of three antiemetic combinations for the prevention of postoperative nausea and vomiting. Anesth Analg 2002; 95:1590-1595.

12. De la Torre A, Rubial M. Anestesia en cirugía ambulatoria. Criterios de alta hospitalaria. ANALES Sis San Navarra 1999; 22: 101-106.

13. Oksuz H, Zencirci B, Ezberci M. Comparison of the effectiveness of metoclopramide, ondasetron, and granisetron on the prevention of nausea and vomiting after laparoscopic cholecystectomy. J Laparoendosc Adv Surg Tech A. 2007 17: 6.

14. Lee A, Gin T, Lau A, Floria F. A Comparison of patients and health care professionals preferences for symptoms during immediate postoperative recovery and the management of postoperative nausea and vomiting. Anesth Analg 2005; 100:87-93.

15. Fujii, Y. Prophylaxis of postoperative nausea and vomiting in patients scheduled for breast surgery. Clin Drug Invest 2006; 26: 427-437.

16. Hannaoka K, Toyooka H, Ohashi Y. Efficacy of profilactic intravenous granisetron in postoperative emesis in adults. J Anesth 2004; 18:158-165.

17. Kovac A. Management of postoperative nausea and vomiting in children. Pediatr Drugs 2007; 9: 47-69.

18. Ramírez D, Ros J. Prevención de las náuseas y vómitos postoperatorios en cirugía ginecológica mediante tres dosis fijas de metoclopramida, droperidol o placebo. Rev Esp Anestesiol 2001; 48: 2.

19. McKeage K, Simpson D, Wagstaff, A. Intravenous droperidol: A review of its use in the management of postoperative nausea and vomiting. Drugs 2006; 66: 2123-2147.

20. Piper S, Suttner S, Röhm K, Maleck W, Larbig E, Boldt J. Dolasetron, but not metoclopramide prevents nausea and vomiting in patients undergoing laparoscopic cholecystectomy. Can J Anesth 2002; 49: 1021-1028.

21. Abali H, Elik I. Tropisetron, ondansetron, and granisetron for control of chemotherapy-induced emesis in turkish cancer patients: A comparison of efficacy, sideeffect profile, and cost. Cancer Invest 2007; 25:135-139.

22. Quaynor H, Raeder J. Incidence and severity of postoperative nausea and vomiting are similar after metoclopramide $20 \mathrm{mg}$ and ondansetron $8 \mathrm{mg}$ given by the end of laparoscopic cholecystectomies. Rev Acta Anaesthesiol Scand 2002; 46: 109-113.

23. Gupta V, Wakhloo R, Lahori V. Prophylactic antiemetic therapy with ondansetron, granisetron and metoclopramide in patients undergoing laparoscopic cholecystectomy under general anaesthesia. Internet Journal of Anesthesiology 2007; $14: 1-5$.

24. Aapro M, Thuerlimann B. A randomized double-blind trial to compare the clinical efficacy of granisetron with metoclopramide both combined with dexamethasone in the prophylaxis of chemotherapy-induced delayed emesis. Ann Onc 2003; 14: 291-297.

25. Apfel C, Korttila K, Abdalla M, Kerger H, Turan A, Vedder I, Zernak $\mathrm{C}$, et al. A factorial trial of six Interventions for the prevention of postoperative nausea and vomiting. N Engl J Med 2004; 350: 2441-2451.

26. Hamadani M, Chaudhary L, Awan F, Khan J, Kojouri K, Ozer $\mathrm{H}$, et al. Management of platinum-based chemotherapy induced acute nausea and vomiting: is there a superior serotonin receptor antagonist?. J Oncol Pharm Practice 2007; 13: 2.

27. Elhakim M, Nafie $M$, Mahmoud K, Atef A. Dexamethasone $8 \mathrm{mg}$ in combination with ondansetron 4 mg appears to be the optimal dose for the prevention of nausea and vomiting after laparoscopic cholecystectomy. Can J Anesth 2002; 49: 922-926.

28. Smith I, Walley G, Bridgman. Omitting fentanyl reduces nausea and vomiting, without increasing pain, after sevoflurane for day surgery. Eur J Anaesthesiol 2008 25: 790-799.

Translate by: Natalia Porras 
Table 1. Proportion of antiemetics used as prophilactic monotherapy (PONV), according to surgical procedure

\begin{tabular}{|lccccc|}
\hline & Dexamethasone & Granisetron & Metoclopramide & $\begin{array}{c}\text { Granisetron }+ \\
\text { others }\end{array}$ & Others \\
Abdominal & 7 & 60 & 0 & 33 & 0 \\
Gynecologic & 4 & 68 & 5 & 18 & 5 \\
Laparoscopic & 3 & 31 & 6 & 58 & 3 \\
Orthopaedic & 10 & 39 & 3 & 32 & 16 \\
Others & 7 & 53 & 5 & 27 & 0 \\
Plastic & 11 & 43 & & & \\
& & & & & \\
\end{tabular}

Table 2. Number of occasions in which different antiemetics were used after PONV, and their effectiveness

\begin{tabular}{|lccc|}
\multicolumn{4}{c|}{ PONV, and their effectiveness } \\
\hline \multicolumn{1}{c}{ Antiemetics in case of } \\
PONV & \multicolumn{3}{c|}{ Vomiting after the antiemetic } \\
& & & Total \\
Alizapride & Effective & Ineffective & 1 \\
Levosulpiride & 1 & 0 & 2 \\
Dimenhydrinate & 2 & 0 & 4 \\
Granisetron & 4 & 0 & 29 \\
Granisetron,Dimenhydrinate & 25 & 4 & 2 \\
Granisetron,Metoclopramide & 2 & 0 & 2 \\
Metoclopramide & 1 & 1 & 5 \\
\hline
\end{tabular}

